
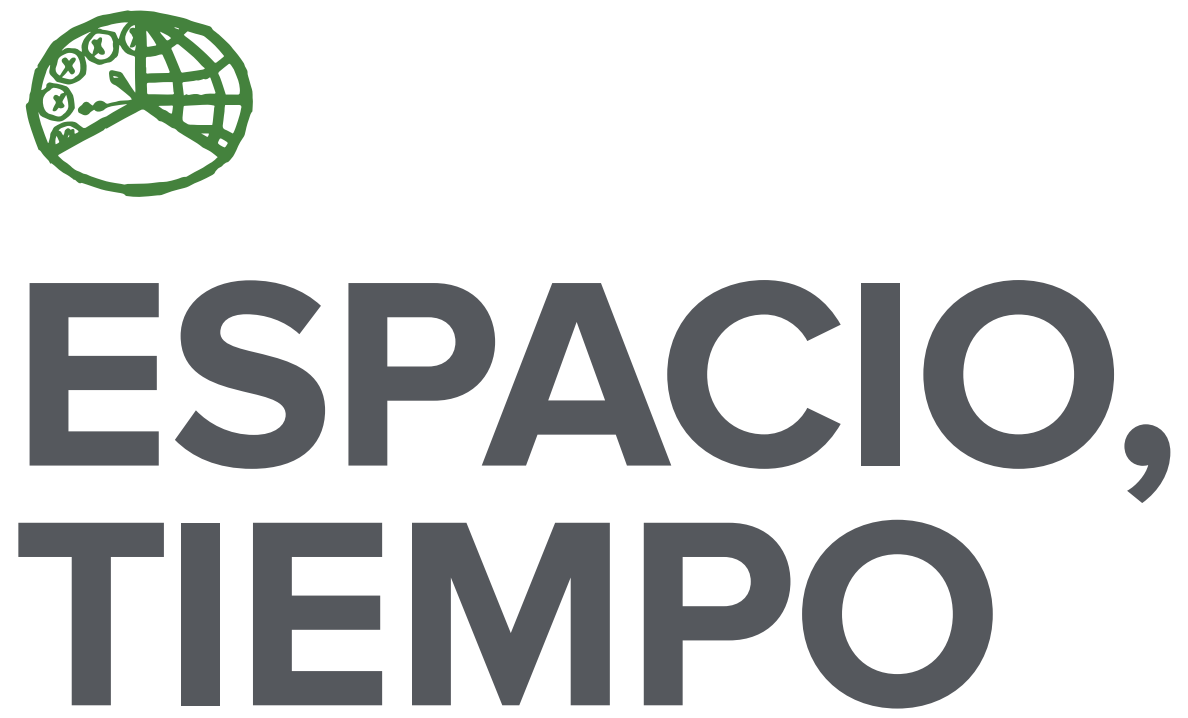

AÑO 2021

ISSN 1130-2968

E-ISSN 2340-146X
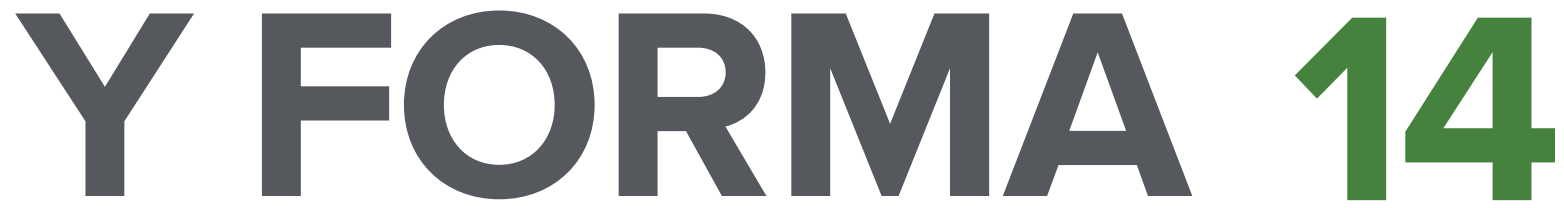

SERIE VI GEOGRAFİA

REVISTA DE LA FACULTAD DE GEOGRAFÍA E HISTORIA 


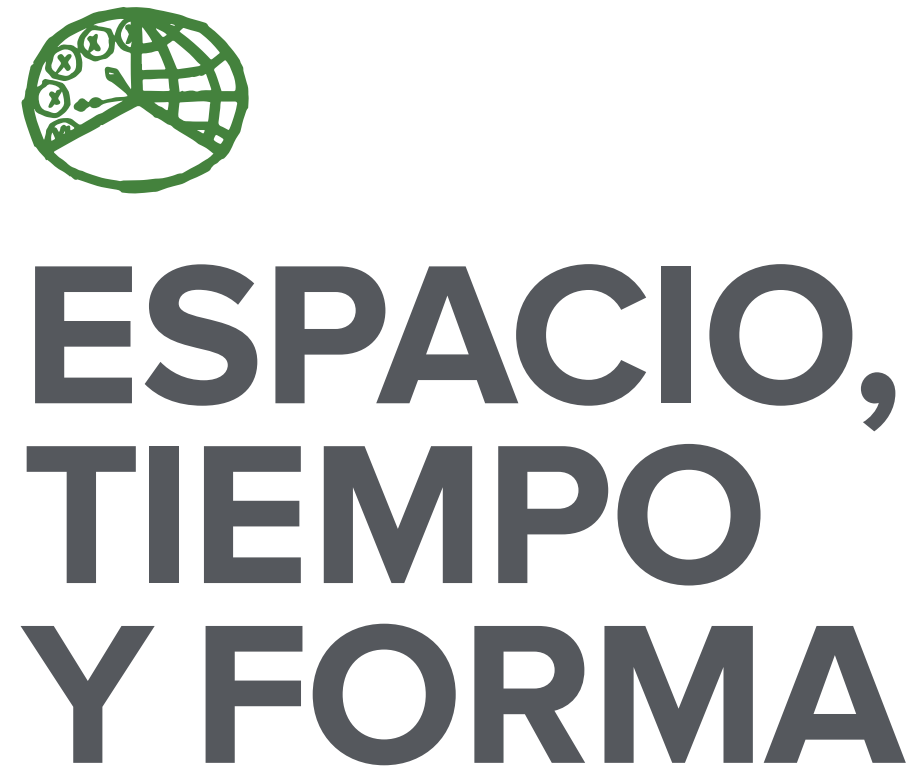

AÑO 2021

ISSN 1130-2968

E-ISSN 2340-146X

SERIE VI GEOGRAFÍA

REVISTA DE LA FACULTAD DE GEOGRAFİA E HISTORIA

DOI: https://doi.org/10.5944/etfvi.14.2021

\section{UחED}

UNIVERSIDAD NACIONAL DE EDUCACIÓN A DISTANCIA 
La revista Espacio, Tiempo y Forma (siglas recomendadas: ETF), de la Facultad de Geografía e Historia de la UNED, que inició su publicación el año 1988, está organizada de la siguiente forma:

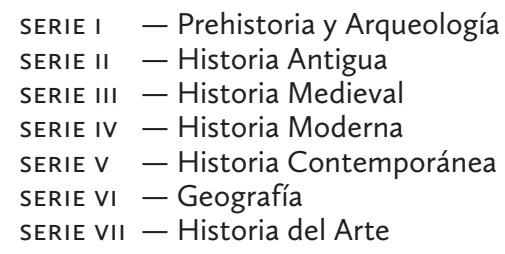

Excepcionalmente, algunos volúmenes del año 1988 atienden a la siguiente numeración:

$$
\begin{aligned}
& \mathrm{N}^{\circ} 1 \text { - Historia Contemporánea } \\
& \mathrm{N}^{\circ} 2 \text { - Historia del Arte } \\
& \mathrm{N}^{\circ} 3 \text { - Geografía } \\
& \mathrm{N} .^{\circ} 4 \text { - Historia Moderna }
\end{aligned}
$$

ETF no se solidariza necesariamente con las opiniones expresadas por los autores.

\author{
UNIVERSIDAD NACIONAL DE EDUCACIÓN A DISTANCIA \\ Madrid, 2020 \\ SERIE VI - GEOGRAFÍA N. ${ }^{\circ} 14,2021$ \\ ISSN 1130-2968 - E-ISSN 2340-146x \\ DEPÓSITO LEGAL \\ $M-21.037-1988$ \\ URL \\ ETF VI · GEOGRAFÍA · http://revistas.uned.es/index.php/ETFVI \\ DISEÑO Y COMPOSICIÓN \\ Carmen Chincoa Gallardo · http://www.laurisilva.net/cch \\ Impreso en España · Printed in Spain
}




\section{ARTÍCULOS · ARTICLES}





\title{
ROGATIVAS PRO-PLUVIA EN LA CATEDRAL DE ORIHUELA: LA SEQUÍA EN ORIHUELA DURANTE EL SIGLO XVII
}

\section{ROGATIVE PRO-PLUVIA IN THE CATHEDRAL OF ORIHUELA: THE DROUGHT IN ORIHUELA DURING THE 17TH CENTURY}

\author{
Gemma Ruiz Ángel ${ }^{1}$ y Mariano Cecilia Espinosa² \\ Recibido: 29/01/2021 Aceptado: 27/07/2021 \\ DOI: https://doi.org/10.5944/etfvi.14.2021.29590
}

\section{Resumen}

Durante el siglo XVII la Catedral de Orihuela fue el escenario de múltiples rogativas relacionadas en la mayoría de los casos con los infortunios que sufría el territorio del Sur valenciano. En este trabajo se estudian aquellas relacionadas con la carestía de agua denominadas pro-pluvia. El análisis de las mismas desde la óptica del comportamiento humano nos ayuda a comprender la climatología de un siglo especialmente dramático para la antigua Gobernación de Orihuela.

Palabras clave

Climatología; rogativas; sequía; Orihuela; catedrales.

\begin{abstract}
During the seventeenth century, the Cathedral of Orihuela was the scene of multiple prayers related in most cases to the misfortunes suffered by the southern Valencian territory. In this work those related to water scarcity called pro - pluvia are studied. Their analysis from the perspective of human behavior helps us understand the climate of a particularly dramatic century for the former Orihuela Government.
\end{abstract}

Keywords

Climatology; prayers; drought; Orihuela; catedrales.

1. Doctora en Geografía Humana. Conservadora del Museo de Arte Sacro de Orihuela. gemma@museodeartesacro.es; ORCID: https://orcid.org/orcid.org/0000-0003-2753-2069

2. Doctor en Historia del Arte por la Universidad de Murcia y doctor en Geografía Humana por la Universidad de Alicante. Director técnico y conservador del Museo Diocesano de Arte Sacro de Orihuela, profesor asociado de Historia del Arte de la Universidad de Murcia; mariano.cecilia@um.es; ORCID: https://orcid.org/orcid. org/0000-0002-8524-1991 


\section{INTRODUCCIÓN}

Los condicionantes geográficos definen el carácter, las costumbres y, en general, la propia identidad de los territorios. El ámbito de este estudio, el sur valenciano, estará marcado por la presencia del río Segura y su huerta, que determinó desde época islámica la condición agraria de la sociedad de la antigua Gobernación de Orihuela, fundamentada en una aristocracia terrateniente con grandes posesiones en el Bajo Segura, como han estudiado Gil Olcina y Canales Martínez (2007) y Millán (I999).

Durante la Edad Media y Moderna, los períodos de sequía se alternaron con situaciones extremas desde el punto de vista climático con la presencia asidua de lluvias torrenciales que en muchos casos derivaban en crecidas del caudal del Segura, a menudo catastróficas, como fue la acaecida en i879, bautizada como la Riada de Santa Teresa. Las precipitaciones, por su carestía o abundancia, fueron motivo de preocupación, al igual que las plagas asociadas, significativamente, las de langosta, y otros infortunios que menoscababan la salud de la población, como eran las epidemias o catástrofes como los terremotos (Canales, 1989).

Los hombres de aquel tiempo buscaron refugio ante las adversidades e infortunios en la misericordia divina encomendándose a santos, mártires, o a la propia Virgen, para que, a través de su intercesión, protegiera a la comunidad local como destacan Canales y Mellis (I999). Para ello, ya desde prácticamente la Reconquista, se hicieron habituales los conjuros y las rogativas como rituales institucionalizados que pretendían la protección de la ciudad, el campo y la huerta con el fin de evitar ruina, muerte y desolación.

\section{OBJETO DE ESTUDIO, FUENTES DOCUMENTALES Y METODOLOGÍA}

En este trabajo se analizan las distintas rogativas públicas que se efectuaban por motivo de carestía de agua en el mediodía valenciano a lo largo del siglo XVII. En este sentido, a través del.examen.de las. actas.capitulares del Cabildo Catedralicio de Orihuela, se puede establecer un seguimiento de los efectos del clima en el espacio de tiempo que abarca este estudio. Para ello, se ha elaborado un cuadro de registro (figura. I) de las distintas rogativas pro - pluvia que se celebraron en el siglo XVII, donde se pueden establecer los períodos de sequía, siguiendo la metodología empleada por Mariano Barriendos i Ballvé en su amplia bibliografía (Barriendos, 2007).

Las fuentes documentales empleadas en este artículo son inéditas, principalmente, las actas capitulares de la Catedral de Orihuela, una serie documental perteneciente al Archivo Catedralicio, fondo actualmente depositado en el Archivo Histórico Diocesano, situado en el Palacio Episcopal - Museo de Arte Sacro de Orihuela. Junto a estos testimonios documentales de las sesiones capitulares se ha utilizado un manuscrito de gran relevancia, el Diccionario Histórico de Acuerdos 
Capitulares ${ }^{3}$, un trabajo monumental compuesto en dos volúmenes durante el siglo XVIII por el canónigo Marcelo Miravete de Maseres. Además, otros documentos del Archivo Catedralicio han sido imprescindibles para conocer con detalles las particularidades del clima en el período de este estudio, significativamente las costumbres y rituales asociados, como el Libro Verde o libro de ceremonial de la Catedral de Orihuela4.

Estas fuentes documentales eclesiásticas, al igual que las municipales ${ }^{5}$, relacionadas directamente con el sistema de rogativas de la ciudad, se caracterizan por su regularidad en cuanto a su constatación en el tiempo y por la fiabilidad como registro exacto de la realización de las ceremonias, así como de las causas y de su evolución inmediata, tal como han evidenciado otros autores en distintos territorios peninsulares y europeos. El análisis de las distintas rogativas demuestra que el ritual marca el grado de intensidad del problema. En estas celebraciones puede variar el ámbito espacial donde se realiza la súplica, las advocaciones intercesoras, el desarrollo de las procesiones así como la representatividad de los participantes en ella. Su estudio permite establecer hasta que punto era preocupante la sequía (figuras 2 y 3). No obstante, las ceremonias varían según la tipología, aunque esto también sucede en ocasiones de plegarias pro - serenitate o por la salud pública, otras modalidades de rogativas que analizaremos en sucesivos trabajos. En este sentido, las rogativas pro - pluvia, organizadas para paliar las situaciones de sequía, son las más frecuentes en la documentación tanto civil como eclesiástica, mientras las rogativas pro - serenitate, focalizadas en la remisión de las lluvias intensas o para contener la crecida del Río Segura, son menos usuales a la hora de su registro, aspecto que está relacionado con el carácter de inmediatez de las mismas, ante fenómenos severos, en muchos casos sorpresivos para la población.

Para el estudio de los distintos períodos de sequía que se documentan durante el siglo XVII en el territorio objeto de estudio se ha empleado el Índice Medio Combinado de Sequía aplicado por otros autores en estudios del mismo carácter focalizados en otros espacios geográficos, metodología que posibilita una aproximación al grado de intensidad de los estiajes a partir del análisis de la frecuencia y la tipología de las rogativas celebradas en momentos determinados y la comparación con los valores medios de la centuria (Romero y Mayer, 2002).

3. ARCHIVO DIOCESANO DE ORIHUELA (en adelante A. D. O.). Fondo Archivo Catedralicio de Orihuela. Diccionario $2^{\circ}$ Histórico de Acuerdos Capitulares. Sig.: 927.

4. A. D. O. Fondo Archivo Catedralicio de Orihuela. Libro Verde. Sig.: 1100.

5. Principalmente, las actas municipales y la serie de correspondencia del consell oriolano. 
TABLA. 1. CUADRO DE CLASIFICACIÓN DE ROGATIVAS POR AGUA, -PRO - PLUVIA Y PRO - SERENITATECorrespondientes Al Período 1635 - $1713^{6}$. Elaboración Propia. Fuente: A. D. O. Fondo Archivo Catedralicio de Orihuela. Actas Capitulares

\begin{tabular}{|c|c|c|c|c|}
\hline CRONOLOGÍA & TIPO DE ROGATIVA & мотIVo & INTENSIDAD & $\begin{array}{l}\text { ADVOCACIÓN } \\
\text { INTERCESORA }\end{array}$ \\
\hline 1625 , enero, 15 & Pro-Pluvia & Sequía & $\begin{array}{l}\text { N3. Grave /Muy } \\
\text { grave }\end{array}$ & $\begin{array}{l}\text { Virgen de } \\
\text { Monserrat }\end{array}$ \\
\hline $\begin{array}{l}1635, \text { marzo, } 8 . \\
1635, \text { marzo, } 18 .\end{array}$ & Pro-Pluvia & Sequía & $\begin{array}{l}\text { N2. Moderada y } \\
\text { N3. Grave /Muy } \\
\text { grave }\end{array}$ & $\begin{array}{l}\text { Virgen de } \\
\text { Monserrat }\end{array}$ \\
\hline 1653, marzo, 24. & Pro - Pluvia & Sequía & $\begin{array}{l}\text { N3. Grave /Muy } \\
\text { grave }\end{array}$ & $\begin{array}{l}\text { Virgen de } \\
\text { Monserrat }\end{array}$ \\
\hline 1654, abril, 20. & Pro-Pluvia & Sequía & Ni. Leve & $\begin{array}{l}\text { Nuestra } \\
\text { Señora del } \\
\text { Rosario }\end{array}$ \\
\hline 1655, marzo, 4 . & Pro-Pluvia & Sequía & $\begin{array}{l}\text { N3. Grave /Muy } \\
\text { grave. }\end{array}$ & $\begin{array}{l}\text { Virgen de } \\
\text { Monserrat }\end{array}$ \\
\hline 1659, febrero, 13. & Pro-Pluvia & Sequía & $\begin{array}{l}\text { N3. Grave /Muy } \\
\text { grave. }\end{array}$ & $\begin{array}{l}\text { Nuestra } \\
\text { Señora del } \\
\text { Rosario }\end{array}$ \\
\hline 1660, abril, 12. & $\begin{array}{l}\text { Pro - Pluvia/ Pro } \\
\text { - Pluvia }\end{array}$ & Sequía & $\begin{array}{l}\text { N3. Grave /Muy } \\
\text { grave }\end{array}$ & $\begin{array}{l}\text { Virgen de } \\
\text { Monserrat }\end{array}$ \\
\hline 1662, marzo, 6 . & Pro - Pluvia & Sequía & Ni. Leve. & $\begin{array}{l}\text { Virgen de } \\
\text { Monserrat }\end{array}$ \\
\hline 1666 & Pro - Pluvia & Sequía & $\begin{array}{l}\text { N3. Grave /Muy } \\
\text { grave }\end{array}$ & $\begin{array}{l}\text { Virgen de } \\
\text { Monserrat }\end{array}$ \\
\hline 1667, diciembre 29. & Pro-Pluvia & Sequía & $\begin{array}{l}\text { N3. Grave /Muy } \\
\text { grave }\end{array}$ & $\begin{array}{l}\text { Virgen de } \\
\text { Monserrat }\end{array}$ \\
\hline 1680, febrero, 28. & Pro - Pluvia & Sequía & $\begin{array}{l}\text { N1. Leve. N3. } \\
\text { Grave /Muy } \\
\text { grave. }\end{array}$ & $\begin{array}{l}\text { Nuestra } \\
\text { Señora del } \\
\text { Rosario/ } \\
\text { Virgen de } \\
\text { Monserrat }\end{array}$ \\
\hline 1682 & Pro-Pluvia & Sequía & $\begin{array}{l}\text { N3. Grave /Muy } \\
\text { grave }\end{array}$ & $\begin{array}{l}\text { Virgen de } \\
\text { Monserrat }\end{array}$ \\
\hline $\begin{array}{l}1690, \text { abril, } 13 . \\
1690, \text { abril, } 20 .\end{array}$ & Pro-Pluvia & Sequía & Ni. Leve & Virgen \\
\hline $\begin{array}{l}\text { 1696, diciembre, } 10 . \\
1696 \text {, diciembre, } 29 .\end{array}$ & Pro-Pluvia & Sequía & $\begin{array}{l}\mathrm{N} 1 \text { y } \mathrm{N} 2 \\
\text { Moderada }\end{array}$ & $\begin{array}{l}\text { Virgen de } \\
\text { Monserrat }\end{array}$ \\
\hline 1700, enero, 28. & Pro - Pluvia & Sequía & $\begin{array}{l}\text { N3. Grave/Muy } \\
\text { grave }\end{array}$ & $\begin{array}{l}\text { Virgen de } \\
\text { Monserrat }\end{array}$ \\
\hline
\end{tabular}

6. A. D. O. Fondo Archivo Catedralicio de Orihuela. Diccionario $2^{\circ}$ Histórico de acuerdos capitulares. Sig.: 927. 


\section{EL ÁMBITO ESPACIAL DE LAS ROGATIVAS Y LAS IMÁGENES INTERCESORAS}

En el ámbito urbano y eclesiástico la Catedral de Orihuela representaba el corazón espiritual no sólo de la ciudad sino de la diócesis como iglesia madre del resto de parroquias del obispado, y con el peso simbólico e institucional de ser la sede de la cátedra del obispo, era el único espacio sagrado desde donde se exhortaba y se invocaba la protección de la Virgen, los santos y los mártires ante la sequía, la inundación y otros infortunios que sufría la población. Su gobierno, el Cabildo Catedralicio, era la corporación facultada para organizar las rogativas. Los representantes concejiles solicitaban a menudo que se organizaran las rogativas, -recogiendo en el caso de las sequías la preocupación de los labradores-, mientras, el obispo acompañaba en las imploraciones en caso de extrema gravedad junto a las comunidades religiosas.

La forma y el modo del ritual ayuda a determinar el grado de intensidad del problema. En primera instancia, se documenta que se celebraban oraciones y plegarias en el interior de la Catedral. En el caso de que su magnitud fuera mayor se realizaban procesiones claustrales dentro del templo catedralicio, siempre con la Virgen como advocación intercesora. El espacio sagrado, en este caso el catedralicio, se sobrepasaba cuando la situación se extremaba en gravedad y se convocaba la procesión general, aunque el escenario de la salida y de la llegada de la misma seguía siendo la seo. El recorrido de estas procesiones públicas lo documentamos en una rogativa pro - pluvia celebrada el 29 de diciembre de i667 con la imagen de Nuestra Señora de Monserrate. Las actas capitulares especifican el itinerario a seguir: iniciaba el recorrido desde la Puerta de los Perdones de la Catedral, -el espacio donde se inicio la consagración del templo en 1598 -, para ir en dirección hasta el arrabal de San Juan, donde se localizaba el Monasterio de San Juan de la Penitencia de las Hermanas Clarisas, para regresar por la Puerta Nueva hacia la Catedral entrando la procesión por la puerta del Loreto, tras acudir previamente al convento de la Trinidad7. Un mes después, el i2 de enero de i668 se realizó otra procesión general para devolver a la Virgen de Monserrate a su ermita, esta vez como acción de gracias, dando fin a la rogativa, tal como indica el documento ${ }^{8}$.

La invocación a la Virgen en las distintas plegarias por sequía fue constante durante todo el siglo XVII. Las advocaciones predilectas del Cabildo Catedralicio, la Virgen del Rosario, considerada como patrona de los capitulares oriolanos, y la creciente devoción a Nuestra Señora de Monserrat, fueron las imágenes protagonistas de estos rituales y el objeto de la devoción de los fieles en momentos de preocupación y angustia.

La Virgen del Rosario se representó a través de una magnífica escultura en plata sobredorada realizada en torno a I582 - I585 por el platero Miguel de Vera. La imagen, conservada actualmente en el Museo Diocesano de Arte Sacro de Orihuela, se

7. A. D. O. Fondo Archivo Catedralicio de Orihuela. Diccionario $2^{\circ}$ de Acuerdos capitulares. Sig.: 927.

8. A. D. O. Fondo Archivo Catedralicio de Orihuela. Diccionario $2^{\circ}$ de Acuerdos capitulares. Sig.: 927. «que en el domingo este presente el santísimo y por la tarde se haga procesión general restituyendo a su casa a la santísima virgen de Monserrate, y que se convoque las comunidades. Fue concluir las rogativas». 
empleaba en las procesiones claustrales dada su ambivalencia como Virgen del Rosario e Inmaculada Concepción, al poseer dos juegos distintos de manos que permitía el cambio de advocación. En I633 - I634, el Cabildo Catedralicio adquirió una escultura en madera policromada y estofada realizada por el escultor Bernardo de Aguilar que preside actualmente el retablo del Rosario construido en el siglo XVIII.

No obstante, para el Cabildo Catedralicio y para la propia ciudad, la imagen de Nuestra Señora de Monserrate fue la advocación intercesora ante epidemias, inundaciones, sequías, terremotos, plagas, ... significativamente, a partir del siglo XVIl. Las rogativas que se hacían a esta imagen se realizaban en el templo catedralicio, en caso de gravedad, se llevaban a cabo procesiones generales por la ciudad con la citada efigie.

\section{ROGATIVAS PRO - PLUVIA DURANTE EL SIGLO XVII: DÉCADAS INTERMINABLES DE SEQUİAS}

Las rogativas pro - pluvia nos proporcionan información de relevancia paleoclimática en el territorio objeto de este estudio. El análisis de los distintos rituales permite establecer distintos niveles de intensidades que ayudan a comprender la problemática, en este caso el grado de sequedad. En este sentido, se han establecido tres niveles de acuerdo a las distintas informaciones que nos proporcionan las actas capitulares de la Catedral, que se resumen en la Tabla 2.

En el Libro Verde de la Sacristía ${ }^{9}$ conservado en el Archivo Diocesano de Orihuela, se puede encontrar la descripción que describe en el siglo XVIII el modo en el que se realizaba la plegaria pro - pluvia, en él se especifican las imágenes de la Virgen de Monserrate y de Nuestro Padre Jesús Nazareno del convento franciscano de Santa Ana, ésta ultima advocación no aparece ligada a este tipo de rogativas en el siglo XVII, es ahora en el siglo XVIII cuando se encuentra en igual condición que la devoción mariana: «la Virgen de Monserrate, en primera instancia, se trasladaba desde su santuario a la Catedral para realizar dentro de la iglesia y los días que fueran necesarios las imploraciones para el cese de la sequía y en segundo lugar, si la sequedad del tiempo persistía, se recurría a la imagen de Nuestro Padre Jesús que bajaba desde el convento de Santa Ana hasta la parroquial de las Santas Justa y Rufina donde se llevaban a cabo las funciones acostumbradas de rogativa. En el caso de sequía muy grave se realizaba una procesión por las calles de la ciudad con ambas imágenes» (Cecilia, 2015). A esta sucesión de plegarias se unía la del patrón del Reino, San Vicente Ferrer, pero solo en caso de que la sequía alcanzara un nivel alto, tal como especifica el acuerdo del Cabildo Catedralicio de 7 de marzo de I765. Aunque estos últimos datos corresponden a mediados del siglo XVIII, podemos observar como los inicios de la celebración de las rogativas pro - pluvia del siglo XVII nos muestra prácticamente la misma ejecución dependiendo del grado de necesidad.

Volviendo al período de estudio, el siglo XVII en el mediodía valenciano fue una centuria marcada por la incidencia de la peste valenciana de I648 y la epidemia

9. A. D. O. Fondo Archivo Catedralicio de Orihuela. Libro Verde. Sig.: 1100. 
de i678 que menoscabo la población y la economía de este territorio. Frente al esplendor del quinientos, la antigua Gobernación de Orihuela sufrió no sólo estas dos graves incidencias de salud pública sino graves inundaciones como al de San Calixto en r65I o constantes sequías tal como se expone a continuación.

TABLA. 2. CUADRO DE NIVELES DE ROGATIVAS PRO - PLUVIA (SEQUíAs). ELABORACIÓN PROPIA.

Fuente: Actas Capitulares del Cabildo Catedralicio de Orihuela

\begin{tabular}{|c|c|c|c|c|c|}
\hline NIVEL & INTENSIDAD & CEREMONIA & $\begin{array}{l}\text { ADVOCACIÓN } \\
\text { INTERCESORA }\end{array}$ & ESPACIO & ORGANIZACIÓN \\
\hline 0 & Prevención & $\begin{array}{l}\text { Bendición de } \\
\text { los términos/ } \\
\text { festividad de las } \\
\text { Rogaciones }\end{array}$ & Vera Cruz & $\begin{array}{c}\text { Cruz de la } \\
\text { Muela (Monte) }\end{array}$ & $\begin{array}{l}\text { Cabildo } \\
\text { Catedralicio }\end{array}$ \\
\hline 1 & Leve & $\begin{array}{l}\text { Oraciones y rezos. } \\
\text { Rosario. }\end{array}$ & $\begin{array}{l}\text { Nuestra Señora del } \\
\text { Rosario o a la Virgen } \\
\text { de Monserrat. } \\
\text { Exposición del } \\
\text { Santísimo y reliquias. }\end{array}$ & Catedral & $\begin{array}{l}\text { Cabildo } \\
\text { Catedralicio }\end{array}$ \\
\hline 2 & Moderada & $\begin{array}{l}\text { Misas de gozos } \\
\text { y Procesiones } \\
\text { claustrales }\end{array}$ & $\begin{array}{l}\text { Nuestra Señora del } \\
\text { Rosario }\end{array}$ & Catedral & $\begin{array}{l}\text { Cabildo } \\
\text { Catedralicio }\end{array}$ \\
\hline 3 & $\begin{array}{c}\text { Grave/Muy } \\
\text { grave }\end{array}$ & $\begin{array}{l}\text { Procesión general } \\
\text { (Hasta la Iglesia de } \\
\text { Monserrate) }\end{array}$ & Virgen de Monserrat & Ciudad & $\begin{array}{l}\text { Cabildo } \\
\text { Catedralicio con } \\
\text { la participación } \\
\text { del Obispo, } \\
\text { el Consell los } \\
\text { conventos y las } \\
\text { parroquias }\end{array}$ \\
\hline
\end{tabular}

\subsection{PERÍODO $1625-1635$}

El primero de los estiajes que se documentan en este estudio se produce en I625, cuando el i6 de enero de aquel año, las actas del Cabildo Catedralicio recogen el acuerdo de realizar una procesión general con la Virgen de Monserrate como rogativa pública por agua ${ }^{\text {Io }}$. En este sentido, dentro de la clasificación de intensidades que se ha elaborado para el sistema de rogativas de la Catedral de Orihuela, nos encontramos con un problema de sequedad grave dado que se recurre al ceremonial que evidencia la mayor severidad: la procesión general por las calles de la ciudad con la máxima representación eclesiástica, el obispo, y civil, el consell municipal.

Desde entonces, y por espacio de diez años, no se tienen noticias de rogativas pro - pluvia en la catedral oriolana. No será hasta I635 cuando de nuevo hay

10. A. D. O. Fondo Archivo Catedralicio de Orihuela. Libro de acuerdos capitulares n ${ }^{\circ} 8.16$ de enero de 1625 . F. 360 - v. Sig.: 874. «que «es fassa proceso a Monserrat per aigua lo diumenge que ve». 
constancia documental de la organización por parte del Cabildo Catedralicio de rogativas por agua de distintas intensidades, como se analizará a continuación ${ }^{\text {II }}$.

El I5 de marzo de aquel año se acordó realizar una procesión general, por tanto, la situación debía ser grave. Una vez tomado el acuerdo, se envío embajada tanto al prelado de la diócesis ${ }^{12}$ como al consell municipal. Asimismo, se determinó que se convocara a todos los conventos y que se comunicara que, de acuerdo a la concordia, la procesión fuese a la iglesia de Nuestra Señora de Monserrate ${ }^{13}$. Con respecto a esta resolución del cabildo, el canónigo Colom se opuso, mientras se nombraron a los canónigos Alenda, Montaner, Angulo y Alonso para la defensa en caso de que se promoviera algún litigio por razón del acuerdo con el obispo o con el vicario general ${ }^{14}$.

El i6 de marzo en sesión capitular los canónigos detallan la situación: el ocho de marzo habían acordado la realización de una rogativa pro - pluvia tras realizar misas de gozo con procesión claustral para que nostre Sr fos servit de donarnos aygua y viendo que la necesidad imperaba y que los sembrados se estaban perdiendo, los justicia y jurados de la ciudad por medio de Joan Soler de Cornella, caballero jurado, envió una embajada al cabildo pidiendo que se hiciesen procesiones y otras rogativas públicas para que nre Señor remedie dita necessitat de aygua. Y en ejecución de la petición el Cabildo Catedralicio resolvió que se hiciera una procesión general para lo cual dieron razón al obispo con el fin de determinar el quo y el qua de la rogativa a través de la embajada del Pavorde Pau Ruiz y Rosell y el canónigo Luis Masquefa. El prelado dio respuesta a la embajada, señalando que la procesión que el Cabildo había determinado realizar pro - pluvia se hiciese en los términos que quisieran pero que tuviesen en cuenta que podía haber algún inconveniente por razón del pleito de causa que llevaban el convento y frailes de San Gregorio con el convento y frailes de San Agustín, ante esta situación el pavorde y el cabildo acordaron prorrogar y diferir la procesión por un tiempo breve para que el prelado pudiera comprender las pretensiones de los religiosos. El cabildo para agradar al obispo prorrogó la procesión por diez días hasta el domingo siguiente.

En el día de la reunión, el i 6 de marzo, los capitulares enviaron una embajada per medio del canónigo Lope Rois a Francisco Piquer, sacriste de la catedral, y vicario general por estar ausente el obispo, al encontrase en la ciudad de Alicante, para que concordara con el cabildo el quo y el qua de la procesión según la concordia

11. A. D. O. Fondo Archivo Catedralicio de Orihuela. Libro de acuerdos capitulares. Año 1635. Sig.: 874. «...resolgueren ss del Capitol que per quant hicieren dit las misses dels goins ab sa processo claustral per que mies sr. Fas servit de donarnos aygua...»

12. A. D. O. Fondo Archivo Catedralicio de Orihuela. Libro de acuerdos capitulares. Año 1635. Sig.: 874. «...demanan que es servisen de fer processons y altas rogativas publiques pera que sr. remedie doita necessitat de aygua y en exo de la dita petición los dias de Capitol y quieren que es fasa una processo general para lo que donaren carta al Sr. Bisbe pera determinas el quo y el qua de la dita prosesso que havian determinat dit s».

13. El acuerdo capitular muestra la vigencia en ese momento de una concordia con el obispo para la realización de procesiones.

14. A. D. O. Fondo Archivo Catedralicio de Orihuela. Libro de acuerdos capitulares nº 9. 15 de marzo de 1635 . F. 9 - v. Sig.: 875. «Resolvent que pera lo diumenge primer vinent es faca proceso per aygua. Y que es faca embajada al Sr. Bisbe o a son vicari pera que se execute lo concordat en materia del quo y el qua y que es faca embajada a la ciutat. $Y$ que es convoquen tots los convents y que es comunique conforme la concordia vaja la proseso a Monserrat contradicante lo C. Sr. Colom. Y que se a cas es mogue algún litigi per raho de la present resolucio ab lo Sr. Bisbe o ab son vicari nomenen per la defensa al C. S. Alenda. C. S. Montaner. C. s Angulo. C. S. Alonso». 
que tenían con el prelado. Así pues, concordaron que se hiciera la procesión en la forma acostumbrada a la Iglesia de Nuestra Señora de Monserrate y así se aprobó en sesión capitular. Por otra parte, pidieron al pertiguero de la catedral que convocara a los conventos y a las parroquias de la ciudad para que el domingo i8 de marzo accedieran y fueran al templo catedralicio para hacer la procesión con la solemnidad que similares procesiones era costumbre realizar. En este sentido, se convocaron por escrito a las parroquias de las Santas Justa y Rufina y San Jaume, a lo conventos de San Gregorio, San Francisco, Capuchinos, Carmen, La Merced, Trinitarios y Agustinos ${ }^{15}$. En este sentido, el i8 de marzo, una vez finalizada la procesión, se acordó multar a los conventos de San Francisco y San Gregorio por no participar en la rogativa por agua que se había celebrado ese día, domingo, por la tarde. Asimismo, se sancionó al canónigo Colom con 3 ducados y privación de su función como síndico del cabildo por no querer realizar una embajada al obispo que en días pasados se le encomendó en relación a la procesión pro - pluvia ${ }^{16}$.

Como se puede apreciar, la organización de las procesiones generales de rogativa es muy compleja. Es el obispo el que establece el recorrido, mientras, el cabildo es el encargado de convocar a la participación, en virtud a la concordia establecida en r62I entre el obispo Bernardo Caballero de Paredes y el Cabildo Catedralicio de Orihuela, en donde se establecía: «... que en todas las demás procesiones públicas y generales extraordinarias que se hubiesen de hacer, así por agua como por otra necesidad común, o pública utilidad, toque, y pertenezca el determinar, y señalar, adonde, y, por donde hayan de ir las dichas procesiones al $\mathrm{Rv}^{\mathrm{Mo}}$. Señor Obispo, con tal que no exceda de los límites acostumbrados en las demás procesiones ordinarias, y el llamar, y convocar a las dichas procesiones toque, y pertenezca al dicho cabildo ... ${ }^{17}$ ».

Los problemas relacionados con el modo de celebrar esta procesión general de rogativa y significativamente, la representación de los distintos estamentos, generaba conflictos, algo habitual en la sociedad del Antiguo Régimen, aunque, por el objeto de este estudio, es de mayor significación la movilización que se realiza de todos los estamentos de poder y de representación de la ciudad en esta plegaria, aspecto que denota la relevancia del acto público como máxima exhortación, y la necesidad acuciante de agua que imperaba en aquel momento.

\subsection{PERÍODO $1653-1660$}

Tras más de una década sin noticias sobre la celebración de rogativas pro - pluvia, aspecto que evidencia que este período se caracterizó por la ausencia de sequías, en I653 se documenta de nuevo una plegaria por agua, además, de carácter severo, ya que se organizó una procesión general. En esta ocasión, se convocó como en i635 a la ciudad, al obispo y a las comunidades religiosas para su participación en la súplica

\footnotetext{
15. Ibídem.

16. Ibídem.

17. A. D. O. Fondo Archivo Catedralicio de Orihuela. Libro de Concordias, f. 315.
} 
pública. Del mismo modo, se hizo embajada al obispo para que dispusiera como se debía realizar la procesión, manteniéndose el mismo procedimiento que se llevaba a cabo en las décadas de 1620 y I $630^{18}$. En aquellos momentos, la situación de la ciudad y su territorio debía ser muy complicada, pocos años antes, en I648, Orihuela había sufrido la conocida Peste Valenciana perdiendo en ella prácticamente a la mitad de su población, por lo que el largo estiaje que sufrirá en años sucesivos dificultará la recuperación económica y social de su territorio, provocando una tremenda crisis de subsistencia (García Ballester y Meyer, I973).

En años sucesivos la sequía persiste y las rogativas se suceden a partir de I654 cuando el cabildo acuerda el 20 de abril realizar una rogativa a Nuestra Señora del Rosario, siguiendo la solicitud de las autoridades civiles que veían conveniente su realización, mientras se pensaba que tipo de plegaria debían organizar ${ }^{19}$. Prácticamente un año después, la situación era grave y se mostraba mucha preocupación por la falta de agua que asolaba el término. En este sentido, el cabildo acordó el 4 de marzo de 1655 realizar una procesión general de rogativa pro - pluvia el domingo siguiente por la tarde nombrando a los canónigos Masquefa y Ruiz para que hicieran embajada al obispo y le comunicaran la realización de la procesión en el día y hora señalada, y que el prelado, como era costumbre, estableciese en concordia con los capitulares «lo quo y qua ${ }^{20} »$.

Tras un paréntesis de unos años, el estiaje de nuevo hace su aparición en I659 cuando el consell pide al Cabildo Catedralicio que se realicen rogativas por agua a Nuestra Señora del Rosario, y que en breve espacio de tiempo se organizara una procesión general por la acuciante necesidad que había ${ }^{21}$. En I66o, la situación de sequedad persiste, por lo que de nuevo, tras la solicitud habitual del consell, se convoca una procesión general a Nuestra Señora de Monserrate, con la participación de los representantes municipales y las comunidades religiosas ${ }^{22}$.

18. A. D. O. Fondo Archivo Catedralicio de Orihuela. Libro de acuerdos capitulares. 24 de marzo de 1653 . F. 16 - v. Sig.: 880: «decreverunt que dema en la vesprada es fasa processo per aygua general y que lo Sr. Syndich fasa embaxada a sa lltma per a que diga lo quo y qua, y lo $\mathrm{S}$. President fasa convocar los convents».

19. A. D. O. Fondo Archivo Catedralicio de Orihuela. Libro de acuerdos capitulares. 20 de abril de 1654 . F. 48 V. Sig.: 880: «Decreverunt qe apres completes es fasa una rogativa a Ntra. Sra. del Roser per aygua attento per part de la ciutat se ha demanat qe conve, y entretant es veura quin altra rogativa es podia fer».

20. A. D. O. Fondo Archivo Catedralicio de Orihuela. Libro de acuerdos capitulares. 4 de marzo de 1655. F. 74 V. Sig.: «Decreverunt que es fasa proceso general de pregaries per aygua y nomenen als C. Masquefa y Sr. C. Ruiz pera que fasan embaixada a Sa lltma y signifiquen el qe es fasa dita proceso lo dumenge per la vesprada y es servixca de señalar lo quo y qua».

21. A. D. O. Fondo Archivo Catedralicio de Orihuela, Diccionario $2^{\circ}$ de Acuerdos capitulares. Sig.: 927. «...por embajada de la ciudad acuerdan hacerlas al rosario; y procesion general. En resolver el dia para ella, a 13 de febrero y que el señor sindico haga embajada a la ciudad, informandola de dicho acuerdo y para la accion de gracia por el nacimiento del señor infante de España». Libro de acuerdos capitulares. 13 de febrero de 1659. 253 - v Sig.: 880 : «Decreverunt que es fasen rogatives per aygua a la Mare de deu del Roser comensant dema y es fasse una proceso general quant es resoldra el dia ex quo la ciutat ha fet embaixada per qe ya necessitat.

Decreverunt lo Sr Syndich fasa embaixada a la ciutat en orde a la de susdit y para pendre resolucioen la festa se ha de fer per lo naiximent del Sr. Infant de España».

22. A. D. O: Fondo Archivo Catedralicio de Orihuela. Diccionario $2^{\circ}$ de Acuerdos capitulares. Sig.: 927: «acuerdan los representantes de la ciudad por el día siguiente con procesión a Ntra. Señora de Monserrate, que el sindico avise al ayuntamiento y que los conventos se convoquen.12 de abril». Libro de acuerdos capitulares.13 de abril de 1660. 309 v. Sig.: 880: «Decreverunt que per quant la ciutat ha fet embaixada qe es fasen pregaries per aygua y lo temps esta molt avant per tant ordenen que dema es fasa proceso gnl a nra. Sra. De Monserrat y qe es convoquen los convts y le Syndich avise la ciutat». 
Dos años después, en el año I662, encontramos en las actas capitulares una solicitud de un informe sobre la cantidad de agua que había para conocer si era necesario continuar con las rogativas o por el contrario darlas por concluidas ${ }^{23}$. En aquellos momentos se encontraba la imagen de la Virgen de Monserrate en la Catedral en rogativa en donde se organizó una novena en su honor con misa diaria con el fin de lograr que lloviera en cantidad suficiente para paliar la sequedad. Poco después, comenzó a llover, por lo que se vuelve a solicitar otro informe para conocer si la lluvia registrada era suficiente. En este caso, podemos leer como la imagen de la Virgen es llevada a la Catedral para este fin especificando los días y los protocolos a seguir: «Trajeron a la Virgen Santísima de Monserrate a la Catedral para rogativas por agua, eran 8 o 9 los días destinados para ella...y decretan se cante una misa cada día de gozo, por Sr. Capitular, en la forma que la de los sábados, de la madre de dios, y que sea por su devoción de los Sres. Que se han ofrecido a cantarlas, con otra limosna. 6 de Marzo. Llovió luego y decretaron que el señor presidente se informe si ha sido bastante el agua, que ha caído, y de orden para que cesen las rogativas: por que en el entretanto que esté aquí la virgen Santísima de Monserrate, se presiga en darle gracias, por tan grande merced como se ha servido hacer. I3 Marzo se hizo procesión de Gracia»²4.

En i666, el Cabildo Catedralicio solicitó que se bajaran desde la ermita de Monserrate las andas que portaban los sacerdotes para llevar en procesión a la Virgen en ocasión de plegaria por agua ${ }^{25}$, por lo que de nuevo se organizará una rogativa pro - pluvia. A finales del año I667 se lleva a cabo una procesión general por agua con la imagen monserratina, tal como se expuso en anteriores epígrafes, en donde ya se detalló su recorrido, protocolo y ceremonial. Es un momento que de nuevo es preocupante dado que un breve espacio de tiempo se organizan dos procesiones generales lo que evidencia que la sequía era muy preocupante.

\subsection{PERÍODO $1668-1700$}

Desde I668 hasta I672 no tenemos constancia documental de ninguna rogativa por agua, por lo que podemos intuir que estos años fueron clementes al respecto del estiaje. A partir de $\mathrm{I} 672$, se vuelven a celebrar rogativas pro - pluvia que marcan un nuevo ciclo que abarca desde ese año hasta I70o, las plegarias ya no son exclusivamente por agua sino puntualmente se realizan otras para paliar los episodios de lluvias intensas que motivan la celebración de rogativas pro - serenitate.

En I680, volvemos a encontrar escasez de agua, y en este caso no se traslada a la Virgen de Monserrate a la Catedral, sino que se acudió a su ermita en procesión general el 28 de febrero para realizar rogativas dirigidas a la Virgen, no sin antes

23. A. D. O. Fondo Archivo Catedralicio de Orihuela. Libro de acuerdos capitulares. Año 1662. Sig.: 881: «Decreverunt que los president se informen si la aygua que hay est suficiente done orden cessen las rogativas y es proseguixca en lo que la verge ss ma. De Monserrat estara en esta casa...».

24. Ibídem.

25. A. D. O. Fondo Archivo Catedralicio de Orihuela. Libro de acuerdos capitulares. Año 1666. Sig.: 881 
realizar rogativas pro - pluvia a la Virgen del Rosario ${ }^{26}$. Dos años después, en I682 se indica que se traiga a la Catedral a la Virgen María de Monserrate para rogarle al niño que vuelva a llover ${ }^{27}$.

Tras un paréntesis de ocho años, en I69o se realiza otra rogativa pro - pluvia donde se especifica que ese domingo se expuso el Santísimo Sacramento y las reliquias para que lloviese, aunque las rogativas se hicieron a la Virgen, tal como era costumbre: «que se empiecen mañana a la Madre de Dios para que llueva, si Dios será servido que en el domingo esté el Santísimo presente, y se pongan las reliquias, y se predique Dios nos favorezca con el agua $»^{28}$.

Seis años después, el to de diciembre de I696, la ciudad envió recado solicitando que continuaran las rogativas por la esterilidad de los tiempos y los continuos vientos que azotaban la ciudad, ya que se temía que se perdieran las cosechas de la huerta ${ }^{29}$. La situación persiste, el 29 de diciembre, el consell municipal volvió a dirigirse a los capitulares oriolanos para que se trasladara a Nuestra Señora de Monserrate a la Catedral para realizar ocho días de rogativa por la necesidad de agua y por el fuerte viento que había en aquellos momentos en el término: «Decreverunt, que per quant la ciutat ha vengut ab recado pera que los Ilustres Señores fesen gust de que es portara la Mare de Deu de Monserrat a esta Santa Esglesia per la necesitat que ha avui de aigua com per los grandisims aires que fa per so determinen que es porte la dita Madre de Deu per lo diumenge, y estiga en esta Sta. Esglesia per espai de huit diez y que correga lo gast de la cera per conte de la ciutat $\ldots . . .^{30} »$.

El siglo XVIIl, arrancará con la cruenta Guerra de Sucesión que trajo funestas consecuencias a la ciudad de Orihuela, adepta del archiduque Carlos, una centuria donde la sequía también será protagonista, aspecto que trataremos en sucesivos trabajos, aunque queremos concluir destacando que el nuevo siglo comenzó con una fuerte sequía que motivó que el 29 de enero de i7oo se llevara a cabo una procesión general de rogativa con Nuestra Señora de Monserrate con la participación habitual de los estamentos civiles y eclesiásticos: «Decreverunt. Que es convoquen a les comunitat pera fer la rogativa esta vesprada a Ntra. Señora de Monserrat ${ }^{35}{ }^{1}$.

26. A. D. O. Fondo Archivo Catedralicio de Orihuela, Diccionario $2^{\circ}$ de Acuerdos capitulares. Sig. 927. «que se hagan por agua a la Virgen del Rosario y en el domingo siguiente primero se haga procesión general a Monserrate, y se haga allí rogativa a dicha soberana señora (habla alli a la de Monserrate y la expresa) por agua. 28 Febrero».

27. A. D .O. Fondo Archivo Catedralicio de Orihuela, Diccionario $2^{\circ}$ de Acuerdos capitulares. Sig. 927. «en el domingo primero viniente a esta santa iglesia para que se le hagan rogativas para que ruegue a su hijo precioso nos de agua...».

28. A. D. O. Fondo Archivo Catedralicio de Orihuela. Diccionario $2^{\circ}$ de Acuerdos capitulares. Sig.: 927.

29. A. D. O. Fondo Archivo Catedralicio de Orihuela. Libro de Acuerdos Capitulares. F. 152. Sig.: 883.

30. A. D. O. Fondo Archivo Catedralicio de Orihuela. Libro de Acuerdos Capitulares. F. 150. Sig.: 883.

31. A. D. O. Fondo Archivo Catedralicio de Orihuela. Libro de Acuerdos capitulares. F. 262. Sig.: 883. 


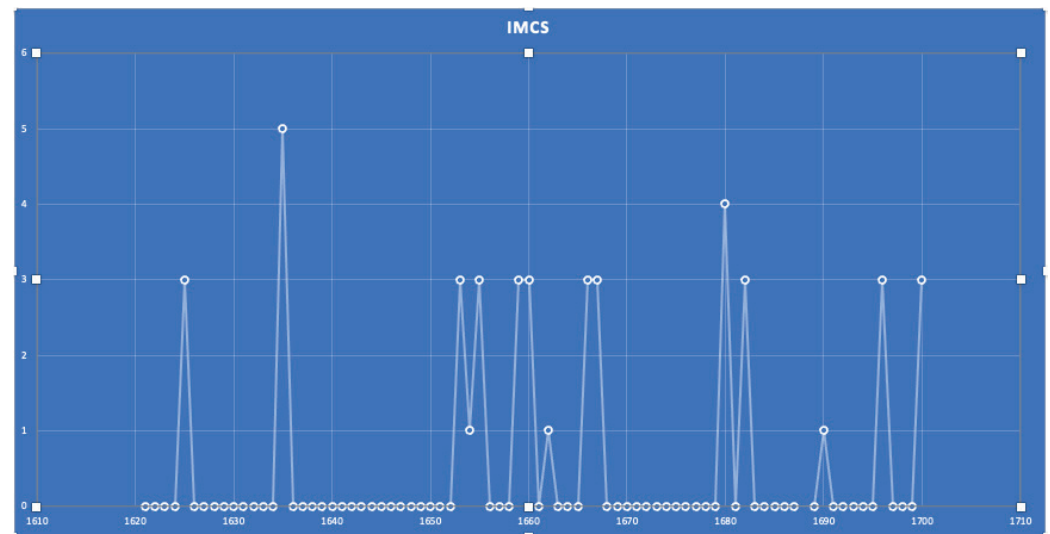

FIGURA. 1. ÍNDICE MEDIO COMBINAdo DE SEQUía (IMCS) EN ORIHUELA (SIGLO XVII). Elaboración propia. Fuente: Actas Capitulares del Cabildo Catedralicio de Orihuela

\section{CONCLUSIONES FINALES}

Las actas capitulares del Cabildo Catedralicio son fundamentales como fuentes primarias para establecer una secuencia cronológica de carestía pluviométrica en un período de la historia donde no existen datos instrumentales. Su estudio a través de la aplicación del Indice Medio Ponderado de Sequía nos posibilita esbozar aspectos relevantes del clima en el mediodía valenciano durante el siglo XVII. Para ello, ha sido imprescindible analizar los ceremoniales de las distintas rogativas, así como su protocolo, ya que ha permitido establecer de forma clara y evidente distintos niveles de intensidad del estiaje a través de los comportamientos de la sociedad y sus instituciones más representativas, tanto civiles como eclesiásticas.

Los datos analizados muestran la variabilidad de la meteorología y la alternancia de fases de sequía, en muchos casos de extrema gravedad, con ciclos donde fueron asiduos los episodios de lluvias intensas y de gran severidad que provocaban catastróficas inundaciones por la salida del cauce del Segura a su paso por la ciudad y la huerta de Orihuela. Las sequías y las inundaciones provocaron graves consecuencias económicas y sociales de un ámbito territorial ya maltrecho por las terribles epidemias de 1648 y 1678 .

En este sentido, los registros históricos muestran una primera mitad del siglo de menor estiaje con dos momentos álgidos de carácter puntual, -en i625 y i635-. Sin embargo, la segunda mitad de la centuria y, significativamente, las décadas de i650 y I660, los períodos de sequedad se prolongan y se encadenan año tras año, la sequía, por tanto, se convirtió en un problema muy grave para el territorio objeto de este estudio, en un contexto particularmente dramático tras la terrible Peste Valenciana de I648.

En la década de I670, los problemas de carestía de agua desaparecen, y no será hasta los inicios de i68o cuando aparezca de nuevo la sequía. Estos episodios darán paso a un período final del siglo caracterizado por un menor número de plegarias pro - pluvia, por lo que estos registros parecen indicar que el último cuarto del siglo XVII fue menos seco que en décadas precedentes, aunque esto no quiere decir que no hubo momentos puntuales donde la sequedad puso en peligro las cosechas de la huerta oriolana (Figura. I). 


\section{BIBLIOGRAFÍA}

Barriendos, M. (I994). El clima histórico de Cataluña. Aproximación a sus características generales (ss. $X V$-XIX), tesis doctoral, Universitat de Barcelona.

BARriendos, M. (I996-I997). El clima histórico de Catalunya (siglos XIV-XIX). Fuentes, métodos y primeros resultados, Revista de Geografía, vol. XXX-XXXI, 69-96.

Barriendos, M. (2000). Climatic variations in the Iberian Peninsula during the late Maunder Minimum (AD I675-I715): an analysis of data from rogation ceremonies, The Holocene, 7, I05-II. https://doi.org/IO.II77/095968369700700IIo

Barriendos, M. (2000). La climatología histórica en España. Primeros resultados y perspectivas de la investigación, en García Cadrón, J. C. (coord.), La reconstrucción del clima de época preinstrumental, Universidad de Cantabria, I5-56.

BARriendos, M. (2007). Variabilidad climática en España a escala peninsular. Reconstrucción a partir de fuentes documentales históricas, en Sousa, Arturo et al. (coords.), El cambio climático en Andalucía: evolución y consecuencias medioambientales, Junta de Andalucía, 45-54.

Canales Martínez, G., Mellis Maynar, A. (I999). Defensa espiritual frente a los riesgos naturales, La catástrofe sísmica de I829 y sus repercusiones, Gregorio Canales Martínez (dir.), Diputación Provincial de Alicante, 213-228. http://hdl.handle.net/10045/48089

Canales Martínez, G (I989). Inundaciones en la Vega Baja del Segura (I875-I925), Avenidas fluviales e inundaciones en la Cuenca del Mediterráneo, Instituto Universitario de Geografía de la Universidad de Alicante, Caja de Ahorros del Mediterráneo, 4I5-433.

Cecilia Espinosa, M (2015). El patrimonio cultural de la ciudad de Orihuela: un modelo para la gestión de los bienes culturales, tesis doctoral, Universidad de Alicante. http://hdl.handle.net/Io045/50358

García Ballester, L., Mayer Benítez, J. M. (I973). La crisis demográfica y de subsistencias y las medidas sanitarias de carácter colectivo en la peste de Orihuela de I648, Primer Congreso de Historia del País Valenciano, celebrado en Valencia del i4 al i8 de abril de I97I, Universitat de Valencia, 40I-4IO.

Gil Olcina, A., Canales Martínez, G. (2007). Residuos de la propiedad señorial en España Perduración y ocaso en el Bajo Segura, Cátedra Arzobispo Loazes, publicaciones de la Universidad de Alicante, (reedición).

http://hdl.handle.net/I0045/I3583

Martínez Gomis, M. (I982). La larga espera de la muerte en una ciudad valenciana del siglo XVII. Orihuela ante la peste de 1676 - I678, Revista de Historia Moderna, Anales de la Universidad de Alicante, 2, I35-I66.

Millán GARCíA VAlERA, J. (I999). El poder de la tierra la sociedad agraria del bajo Segura en la época del liberalismo: 1830-1890, Colección Ensayo e Investigación, Instituto de Cultura Juan Gil-Albert, Diputación Provincial de Alicante.

Romero Martin, L. E., Mayer Suarez, P. (2002). Episodios de sequía en Gran Canaria en el Siglo XVII: análisis de las rogativas como método de reconstrucción climática, Guijarro Pastor, J. A. (Ed.). El agua y el clima. Publicaciones de la Sociedad Española de Climatología, 533-542. 


\section{4

\section{Presentación · Foreword}

\section{Artículos · Articles}

19 Eugenio Climent López y Samuel Esteban Rodríguez

La crisis económica de 2008 en las Denominaciones de Origen Protegidas de vino españolas: efectos y modelos de salida. The 2008 Economic Crisis in the Spanish Protected Designations of Origin of Wine: Effects and Exit Models

4.5 David García-Reyes, EnRICo Marini y Marta Gallardo

Infancia, pobreza y deporte en el desierto de Calama, Chile. Representaciones sociales en «Segundo tiempo, último gol gana» . Childhood, Poverty and Sport in the Desert of Calama, Chile. Social Representations in «Segundo tiempo, último gol gana»

José Antonio González díaz, Benjamín González díaz y Rocío Rosa GARCía

Revisión de los objetivos de los espacios protegidos: el parque natural y reserva de la biosfera de Redes - Review of the Objectives of Protected Spaces: Natural Park and Biosphere Reserve of Redes

Álvaro-Francisco Morote Seguido

Investigación y enseñanza en didáctica de la climatología. Estado de la cuestión (1980-2020) (España) · Research and Teaching in Didactic of Climatology. State of the Art (1980-2020) (Spain)

\section{Gemma Ruiz Ángel y Mariano Cecilia Espinosa}

Rogativas pro - pluvia en la catedral de Orihuela: La sequía en Orihuela durante el siglo XVII · Rogative Pro - Pluvia in the Cathedral of Orihuela: The Drought in Orihuela during the $17^{\text {th }}$ Century

\section{5}

José Ramón Sánchez Holgado

La puesta en valor de los campos de concentración y exterminio nazis como lugar de memoria . Putting Value of the Nazis Extermination and Concentration Camps as a Place of Memory

\section{7}

LAURA Sevilla CuAdrado

La conciencia medio ambiental en el sector del turismo de sol y playa. Un estudio con la técnica Delphi . Environmental Awareness in the Sun, Sea and Sand Tourism Sector. A Study using the Delphi Technique

The Technopolitics of Mapping Dar es Salaam: An Examination of the Technological and Political Motivations of the Humanitarian OpenStreetMap Team La tecnopolítica de la cartografía de Dar es Salaam: Un examen de las motivaciones tecnológicas y políticas del equipo humanitario OpenStreetMap

\section{Reseñas · Book Review}

19 De LÁzaro Torres, María Luisa y Morales Yago, Francisco José (2021). Introducción a la Investigación en Geografía. Pautas para la Elaboración de Trabajos Científicos (An Introduction to Research in Geography. Guidelines for the Preparation of Scientific Papers). UNED, 223 Pp., ISBN: 978-84-362-7689-3. (JuLIO FERNÁNDEZ PORTELA

Fernández Portela, Julio y Hernández García, Ricardo (2021). Sociedad y territorio en Cubillas de Santa Marta: del Catastro de Ensenada a la actualidad. Ayuntamiento de Cubillas de Santa Marta, 259 pp., ISBN: 978-84-09-28428-3. (MIGUEL ÁngEL GarCía VELASCO)

MÉndez GutiérRez del VALLe, R. (2020). Sitiados por la pandemia. Del colapso a la reconstrucción: apuntes geográficos. Revives, 183 pp. (ROSA MECHA

23 MARTín-Roda, Eva María (2021). Geopolítica de los recursos energéticos. Síntesis, 276 pp., ISBN: 9788413571348 ; ISBN Digital: 9788413576626 (AURELIO NiETO CODINA)

235 Moreno BorrelL, S. (2019). La Naturaleza y el Paisaje de Málaga a través de viajeros, naturalistas y científicos. La Serranía, 224 Pp., ISBN: 978-8415588-28-3 (SERGIO REYES CORREDERA)

\section{Imágenes y palabras · Pictures and Words}

\subsection{JULıo López-DavaliLlo LARREA \\ La laguna de Herramélluri. Un humedal renacido . The Herramélluri Lagoon.}

\section{Síntesis de Tesis Doctorales · Summaries of Doctoral Thesis}

\section{Javier Álvarez Otero}

El uso educativo de las Infraestructuras de Datos Espaciales (IDE) para mejorar la responsabilidad social de los ciudadanos del siglo XXI sobre el territorio. Departamento de Didáctica de las Ciencias Experimentales, Sociales y Matemáticas. Universidad Complutense de Madrid. Directora: Dra. Doña María Luisa de Lázaro Torres. Fecha: 10 de diciembre de 2020

\section{José Fernández Álvarez}

Dinámica evolutiva de los usos y coberturas del suelo en la provincia de Salamanca. Análisis comparado y repercusiones en el paisaje rural de cuatro comarcas de estudio. Departamento de Geografía, Universidad Nacional de Educación a Distancia (UNED). Director: Dr. D. Carlos Javier Pardo Abad. Fecha: 27 de mayo de 2021 